\title{
Regulation of mitochondrial NADP-isocitrate dehydrogenase in rat heart during ischemia
}

\author{
Tatiana Popova, ${ }^{1}$ Miguel A.A. Pinheiro de Carvalho, ${ }^{2}$ \\ Larisa Matasova ${ }^{1}$ and Liliya Medvedeva ${ }^{1}$ \\ ${ }^{1}$ Department of Analytical and Medical Biochemistry and Microbiology, Voronezh State University, 394006 Voronezh, Russia; \\ ${ }^{2}$ ISOPlexis / BIOtecMOL, Centre of Macaronesian Studies, Madeira University, 9000-390 Funchal, Portugal
}

Received 17 December 2005; accepted 16 May 2006; Published online: 6 July 2006

\begin{abstract}
The changes in the regulation of at mitochondrial NADP-isocitrate dehydrogenase (NADP-ICDH) in a rat heart during have been analysed. Increase of enzyme activity in the cytosol and mitochondria of the heart ischemia was detected. Catalytic properties of the mitochondrial NADP-ICDH at norm and pathology have been compared on homogeneous enzyme preparations. Enzyme from the normoxic and ischemic heart showed the same electrophoretical mobility and molecular mass. Enzyme isolated from the ischemic heart mitochondria demonstrated higher activation energy and lower thermal stability. NADP-isocitrate dehydrogenase at the normoxic and ischemic conditions exhibited different $\mathrm{K}_{\mathrm{m}}$ for substrates and regulatory behaviour in relation to ATP, ADP, 2-oxoglutarate, citrate, malate, reduced and oxidised glutathione. The inhibitory effect of the $\mathrm{Fe}^{2+}$ and $\mathrm{H}_{2} \mathrm{O}_{2}$ mixture associated with the generation of hydroxyl radicals was lower in the ischemic enzyme. We hypothesise that the specific features of regulation behaviour of NADP-ICDH from the ischemic tissues permits the enzyme to supply NADPH to the glutathione reductase/glutathione peroxidase system. (Mol Cell Biochem 294: 97-105, 2007)
\end{abstract}

Key words: ischemia; oxidative stress; NADP-isocitrate dehydrogenase; enzyme regulation

\section{Introduction}

The role of free radical processes in the aetiology of ischemia and myocardial infarction is widely accepted [1-4]. It is considered that the reactive oxygen species (ROS) formed in mitochondrial and microsomal oxidative reactions contribute to the development of cardiomyocite damage. Mitochondria are a major cellular source of ROS. The generation of superoxide anion depends on the respiration rate and the reduced state of electron chain carriers support the formation of superoxide ion by one-electron transfer reactions $[5,6]$. Additionally, defective oxidative phosphorylation [7], degradation of ATP, xanthine $[8,9]$ and Fe-binding proteins, and free $\mathrm{Fe}^{2+}$ accumulation [10-12] increase the generation of ROS in mitochondria under the ischemic conditions. The glutathione reductase/glutathione peroxidase system (GRGP-system) has been proposed as a main mechanism of ROS-level regulation [10]. This mechanism plays an important role in $\mathrm{H}_{2} \mathrm{O}_{2}$ detoxification and might prevent the formation of more aggressive hydroxyl radical by the Fenton reaction [11]. The activity of the GRGP-system primarily depends on NADPH levels needed for the reposition of the reduced glutathione [13].

Reaction catalysed by the NADP-dependent isocitrate dehydrogenase (NADP-ICDH) plays a key role in NADPH supply in rat cardiomyocites [14]. Using a NIH3T3 cell line, Jo et al. [15] showed that mitochondrial NADP-ICDH acted as an antioxidative enzyme. The two NADP-ICDH isoenzymes in mammalian tissues were shown to differ in their 
distribution, sub-cellular localisation and some molecular and catalytic properties [16-19]. Earlier we reported the properties of the ischemic cytoplasmic NADP-ICDH from a rat heart and showed that enzyme could serve as an alternative to the pentose phosphate pathway as a source of NADPH at pathology [20]. It has not been excluded that the NADPH formed by mitochondrial NADP-ICDH in oxidative decarboxylation of threo-Ds-isocitrate might be essential for NADPH supply of the myocardial GRGP-system. Although, little is known about the functioning of mitochondrial NADP$\mathrm{ICDH}$ in the myocardium, the high catalytic activity and the specific mRNA expression indicates its regulation at gene level under specific conditions [21, 22]. The physiological role of NADP-ICDH in the heart mitochondria is a controversial subject at the present time. Besides the indications that mitochondrial NADP-ICDH may function as an antioxidant there are some evidences suggesting that this enzyme operates in reverse direction of the tricarboxylic acid cycle (TAC). It has been proposed that the reverse flux through NADP-ICDH is coupled with the transhydrogenase reaction and may play a significant role in fine regulation of the TAC activity and in the enhancement of energy production [23].

This study aims to characterise the catalytic properties and regulation of the mitochondrial NADP-ICDH from rat myocardium at normoxia and ischemia and to elucidate the role of the enzyme in cardiomyocites response to the ischemic oxidative stress.

\section{Materials and methods}

\section{Materials}

NADP, ADP, ATP and glutathione were obtained from Reanal, Hungary. D, L-Isocitrate (trisodium salt) and 2oxoglutarate were from Sigma Chemical Company, London, U.K. Tris was supplied by Serva, Germany. CM-Cellulose was purchased from Whatman, London, U.K. CM-Sephadex, Sephadex G-25 and G-150 was from Pharmacia, Uppsala, Sweden. All other chemicals were of the highest analytical grade available.

\section{Experimental procedures}

Healthy male rats of the species, Rattus novergicus albino, weighting 200-250 g maintained on identical diet were used in the experiments. Experimental myocardial ischemia was induced by occlusion of the rats left coronary artery for $45 \mathrm{~min}$ [24]. Control rats have been "sham" operated, by unilateral thoracotomia.

Cell-free extract was prepared by tissue homogenisation in $0.05 \mathrm{M}$ Tris-HCl-buffer, $\mathrm{pH} 7.8$ containing $1 \mathrm{mM}$ EDTA,
0.3 M sucrose. Suspension was filtered through four layers of cheesecloth and centrifuged at 3,500 g for $5 \mathrm{~min}$. The pellet was discarded and supernatant centrifuged at 15,000 $\mathrm{g}$ for 15 min. Final supernatant containing cytoplasm NADP-ICDH activity was discharged. Pellet with intact mitochondria was washed and centrifuged twice in a minimal volume of $0.05 \mathrm{M}$ Tris- $\mathrm{HCl}$ buffer, $\mathrm{pH} 7.8$ containing $0.175 \mathrm{M} \mathrm{KCl}$. The pellet was dissolved in $0.05 \mathrm{M}$ Tris- $\mathrm{HCl}$ buffer, $\mathrm{pH} 7.8$ and used in the purification of mitochondrial NADP-ICDH.

The enzyme reaction was followed spectrophotometrically by measuring the rate of NADPH formation at $340 \mathrm{~nm}$ [16]. The reaction mixture consisted of $0.05 \mathrm{M}$ Tris- $\mathrm{HCl}$ buffer, $\mathrm{pH} 7.8,0.20 \mathrm{mM} \mathrm{MnCl}_{2}, 0.05 \mathrm{mM}$ isocitrate, $0.40 \mathrm{mM}$ NADP. Enzyme unit corresponds to the amount of enzyme, catalysing the formation of $1 \mu \mathrm{mol}$ of NADPH per minute at $25^{\circ} \mathrm{C}$. The protein content of samples was determined according to Lowry et al. [25], with modifications of $\mathrm{Yu}$ and Steek [26].

All purification procedures were carried out at 0 to $+4{ }^{\circ} \mathrm{C}$. After centrifugation and washing, the mitochondrial suspension was treated with $20 \%$ glycerol and $1 \%$ Triton X-100 $(\mathrm{v} / \mathrm{v})$.

Contamination by low weight compounds was avoided by gel-filtration on a Sephadex G-25 column $(1.5 \times 20.0 \mathrm{~cm})$ equilibrated with $0.05 \mathrm{M}$ Tris- $\mathrm{HCl}$ buffer, $\mathrm{pH} 7.8$, containing $0.10 \mathrm{mM}$ EDTA and $0.50 \mathrm{mM} \beta$-mercaptoethanol (buffer A). Fractions containing the highest NADP-IDH activity were joined together and applied to a CM-Cellulose column $(0.5 \times$ $13.0 \mathrm{~cm}$ ) pre-equilibrated with buffer A. Elution of the enzyme during ion-exchange chromatography was performed with the same buffer containing stepwise or linear concentration gradients of $\mathrm{KCl}$. Fractions possessing NADP-IDH activity were loaded onto a Sephadex G-150 column $(2.0 \times$ $45.0 \mathrm{~cm}$ ), previously equilibrated with buffer A. The flow rate of elution was 35,30 and $25 \mathrm{ml} \cdot \mathrm{h}^{-1}$ on each step of purification, respectively. Homogeneity of this enzyme was monitored by electrophoresis in $7.5 \%$ polyacrilamide gel as described by Davis [27] and gels stained with Coomassie Blue R-250 [28].

Electrophoretical homogeneous mitochondrial NADPIDH purified from control, normoxic (86.1-fold purified) and ischemia-induced (104.2-fold) myocardium was used to perform a comparative study of enzyme catalytic and regulatory properties. The molecular mass of NADP-IDH was determined in the presence or absence of isocitrate and $\mathrm{Mn}^{2+}$ ions at non-saturating and saturating concentrations by gelfiltration on Sephadex G-150 [29]. Kinetic parameters were determined by modulating the concentrations of isocitrate, NADP or $\mathrm{Mn}^{2+}$ ions in the presence of a saturating concentration of NADP $(0.40 \mathrm{mM})$, isocitrate $(0.05 \mathrm{mM})$ or $\mathrm{MnCl}_{2}$ $(0.20 \mathrm{mM})$, respectively.

The effect of temperature on the NADP-IDH activity was determined after 5 min-incubation of the purified enzyme in a 
reaction mixture at a temperature range between 10 and $70^{\circ} \mathrm{C}$. Stability of NADP-IDH was estimated by temperature incubation of an appropriated amount of purified enzyme (0.07 $\mathrm{mg}$ of protein per tube). At $20 \mathrm{~min}$ intervals, aliquots were withdrawn and analysed for enzyme activity. Protein denaturation has determined by spectrophotometer measurement of the magnitude of light diffusion value $(\tau)$ at $490 \mathrm{~nm}$.

The enzyme regulation in the presence of adenine nucleotides, TAC intermediates, glutathione, $\mathrm{Fe}^{2+}$ ions and $\mathrm{H}_{2} \mathrm{O}_{2}$ was carried out. Co-operation between metabolite inhibitors, $\mathrm{Fe}^{2+}$ ions and $\mathrm{H}_{2} \mathrm{O}_{2}$, was estimated according to Kurganov [30]. Type and constants of NADP-ICDH inhibition $\left(\mathrm{K}_{i}\right)$ was determined according with Dixon and KornishBouden methods [31].

The statistical significance of the experimental data was determined by analysis of variance followed by Student $t$ tests. Differences between values were considered significant if $P<0.05$. The graphs were plotted using data processed with programs of linear and parabolic approximation.

\section{Results and discussion}

In our previous work [20], we have shown that 45 minutes of ischemia causes an enhancement of free radical processes and total antioxidative activity estimated by chemiluminescence in cytosol and mitochondria of a rat heart. A 1.5 -fold increase of the $\alpha$-tocopherol contents in ischemic mitochondria was also observed. These changes were accompanied by 2.5 - and 1.8-fold increase of NADP-ICDH activity in ischemic mitochondria and cytosol [20,32]. Nevertheless, the control of the free radical processes intensity and total antioxidative activity took place in the presented experiments. NADP-ICDH was isolated from the heart as a whole taking into consideration that during infarction the myocardium lesions were not limited to the zone of ischemia. Several works have shown changes in the non-ischemic zone, which were similar to changes at ischemic disease of heart, specifically in the activation of lipid peroxid oxidation [33].

The mitochondrial NADP-ICDH of ischemic tissue was purified by ion exchange chromatography on DEAECellulose, CM-Cellulose, DEAE-Sepharose and CMSephadex using a linear gradient of $0-200 \mathrm{mM} \mathrm{KCl}$. Fractions with higher enzyme activity were obtained by chromatographic separation in CM-and DEAE-Cellulose. During the elution from DEAE-cellulose columns the NADP-ICDH activity in $155 \mathrm{mM} \mathrm{KCl}$, the fractions were poorly separated from the aconitate hydratase activity (data not shown). Purified NADP-ICDH from normoxic and ischemic mitochondria migrated through the CM-Cellulose columns as a single peak in the presence of 22 and $27 \mathrm{mM} \mathrm{KCl}$, respectively, while the specific activity of enzymes from both mitochondria varied nearly 2.5 times. The enzyme specific activity from the mito- chondria of normoxic and ischemic heart had 15.5 and 38.0 unit $\mathrm{mg}^{-1}$ protein, respectively. Other purification parameters were 86.1 and 105.6 -fold purification or 3.5 and $4.4 \%$ yield, respectively (Table 1). Yield of NADP-ICDH active fractions during elution on the Sephadex G-150 column coincided with a single peak of total protein (data not shown). The analysis of purified NADP-ICDH preparations of both tissues revealed a single protein band with the same electrophoresis' mobility, $\mathrm{R}_{\mathrm{f}} 0.43$ (Fig. 1), which differed from the mobility of the cytosolic isoenzyme from the normoxic or ischemic rat heart, with $\mathrm{R}_{\mathrm{f}} 0.51$ [20]. The purified mitochondrial enzyme were electrophoretically homogenous and appeared be free of cytosolic NADP-ICDH contaminations. The mitochondrial enzyme from the ischemic heart exhibited an increase of 2.5 -fold in the specific activity over the enzyme from normoxic tissue. This result could be related to the observed initial differences in enzyme activity of mitochondrial fractions from the normoxic and ischemic heart detected either by differential centrifugation or ion exchange chromatography. Ischemia-induced increase of NADP-ICDH activity in the mitochondria of a rat heart was consistent with earlier observations for NADP-ICDH from the rat brain cytosol fraction [18]. Correlation between ischemic impairment and rising of NADP-ICDH activity in the cell cytoplasm of a rabbit spinal cord was also reported [34]. Thus, the enhancement in NADP-ICDH activity could occur in different mammalian tissues under ischemic conditions. However, some earlier studies reported the changes in enzyme activity only under pathological conditions [16, 34]. In previous work, we compared the cytosolic enzyme features in normoxic and ischemic tissues and related them to the level of ROS production [20]. Despite of that, the role and features of rat heart mitochondrial NADP-ICDH functioning at ischemia is still far from being understood. In order to elucidate the mechanisms associated with the enzyme activity changes at ischemia, the molecular and catalytic properties of mitochondrial NADP-ICDH from the normoxic and ischemic rat heart were compared.

Vertebrate's NADP-IDH consists of two identical subunits, which are involved in an association-dissociation mechanism of the enzyme activity regulation [34]. The substrate plays a relevant role as modulator of the subunits association or dissociation, as described for the NADP-ICDH from pig liver [35]. However, in the present study, the same molecular mass values have been found in enzyme from normoxic and ischemic rat heart $(77.6 \pm 5.0 \mathrm{kDa})$. These values were the same in the presence as well as in the absence of substrates and cofactors. Therefore, NADP-IDH association-dissociation mechanisms cannot explain the changes in enzyme activity during ischemia. We suggest that the changes in activity of mitochondrial NADP-ICDH under ischemia could be associated with some structural or conformational modifications of the enzyme. The increase in substrate affinity associated with the 
Table 1. Purification of NADP-Isocitrate dehydrogenase from the normoxic and ischemic rat myocardium

\begin{tabular}{|c|c|c|c|c|c|c|}
\hline Purification step & $\begin{array}{l}\text { Exp. } \\
\text { conditions }\end{array}$ & $\begin{array}{l}\text { Total activity } \\
\text { (units) }^{a}\end{array}$ & $\begin{array}{l}\text { Total protein, } \\
(\mathrm{mg})^{a}\end{array}$ & $\begin{array}{l}\text { Specific activity, } \\
\text { (units/mg of } \\
\text { protein) }^{a}\end{array}$ & $\begin{array}{l}\text { Total } \\
\text { yield, } \\
(\%)\end{array}$ & $\begin{array}{l}\text { Times } \\
\text { purified } \\
\text { (total) }\end{array}$ \\
\hline \multirow[t]{2}{*}{ Crude extract } & Normoxia & $8.86 \pm 0.08$ & $48.1 \pm 1.68$ & $0.18 \pm 0.05$ & 100.00 & 1.00 \\
\hline & Ischemia & $17.15 \pm 0.30$ & $48.05 \pm 1.75$ & $0.36 \pm 0.07$ & 100.00 & 1.00 \\
\hline \multirow{2}{*}{$\begin{array}{l}\text { Mitochondria }+ \text { X100 } \\
\text { Triton X100 }\end{array}$} & Normoxia & $1.30 \pm 0.05$ & $3.1 \pm 0.30$ & $0.42 \pm 0.03$ & 14.67 & 2.33 \\
\hline & Ischemia & $3.22 \pm 0.07$ & $3.05 \pm 0.35$ & $1.06 \pm 0.04$ & 18.78 & 2.94 \\
\hline \multirow[t]{2}{*}{ G-25 } & Normoxia & $1.26 \pm 0.03$ & $3.00 \pm 0.55$ & $0.42 \pm 0.04$ & 14.22 & 2.33 \\
\hline & Ischemia & $3.10 \pm 0.02$ & $3.00 \pm 0.40$ & $1.03 \pm 0.02$ & 18.08 & 2.86 \\
\hline \multirow[t]{2}{*}{ CM-cellulose } & Normoxia & $0.67 \pm 0.02$ & $0.24 \pm 0.04$ & $2.79 \pm 0.01$ & 7.56 & 15.50 \\
\hline & Ischemia & $1.54 \pm 0.06$ & $0.23 \pm 0.05$ & $6.70 \pm 0.02$ & 8.98 & 18.61 \\
\hline \multirow[t]{2}{*}{ G-150 } & Normoxia & $0.31 \pm 0.04$ & $0.02 \pm 0.02$ & $15.5 \pm 0.05$ & 3.50 & 86.11 \\
\hline & Ischemia & $0.76 \pm 0.04$ & $0.02 \pm 0.01$ & $38.0 \pm 0.05$ & 4.43 & 105.60 \\
\hline
\end{tabular}

${ }^{a}$ The results are expressed as the means + S.D. derived from three experiments.

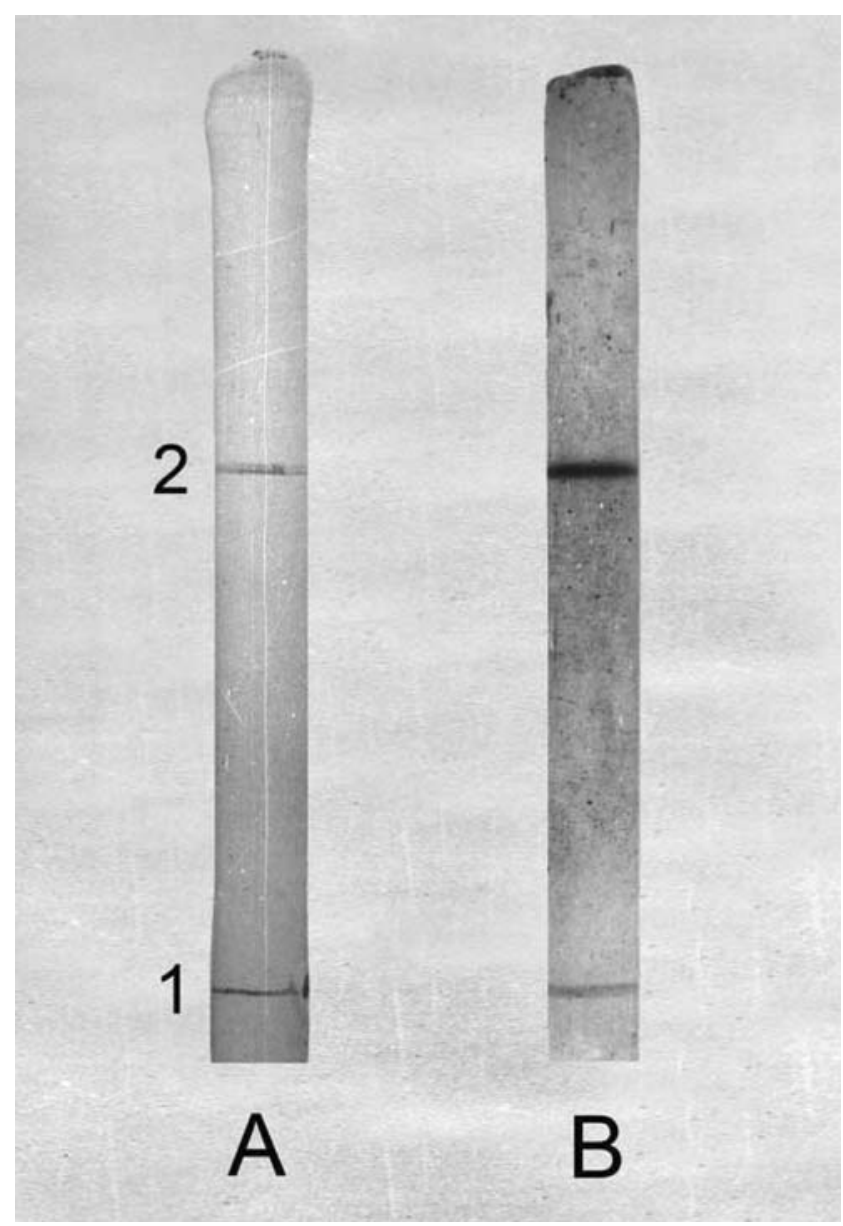

Fig. 1. Polyacrilamide gel electrophoresis of the NADP-isocitrate dehydrogenase from normoxic (a) and ischemic (b) rat heart mitochondria. Band 1 shows a set of marker front. Band 2 - NADP-isocitrate dehydrogenase. Proteins were stained with Coomassie Brilliant Blue R250. changes of $\mathrm{K}_{\mathrm{m}}$ for isocitrate and $\mathrm{Mn}^{2+}$ observed in NADPICDH under ischemia supports this supposition. The values for $\mathrm{K}_{\mathrm{m}}$ of normoxic and ischemic NADP-ICDH to isocitrate, NADP and $\mathrm{Mn}^{2+}$ ions are presented in Table 2. Mitochondrial NADPH-ICDH from ischemic and normoxic heart had different temperature optimums, which were 40 and $50^{\circ} \mathrm{C}$, respectively (Fig 2A). The Arrhenius plot for the enzyme incubation temperature at the intervals between 10 to $40^{\circ} \mathrm{C}$ showed a breakpoint at $30^{\circ} \mathrm{C}$, resulting in activation energy values of $1820 \mathrm{kcal}$ between 10 and $30^{\circ} \mathrm{C}$ and $5936 \mathrm{kcal}$ between 30 and $40^{\circ} \mathrm{C}$ for ischemic NADP-ICDH (Fig. 2B). No breakpoint in the Arrhenius plot for the normoxic enzyme has been identified. The activation energy for the enzyme at the temperature interval between 10 and $50^{\circ} \mathrm{C}$ has $7756 \mathrm{kcal}$. Despite the lower initial activity, the purified normoxic NADP-ICDH showed higher thermostability, at $60-70^{\circ} \mathrm{C}$, than at ischemic conditions. Faster enzyme inactivation and the increase of light diffusion are other parameters confirming these differences (Fig. 2C, D). These results allow us to conclude that mitochondrial NADP-ICDH from the normoxic and ischemic heart were the same enzyme, however, under ischemia the enzyme showed higher substrate affinity and lower temperature stability. Thus, temperature breakpoint, higher energy activation, lower temperature optimum and stability can indicate possible enzyme structure and conformational changes during the ischemia. Some data point out to the structural modifications of NADP-ICDH under oxidative stress. In particular, it was reported that mitochondrial NADP-ICDH contains reduced cysteinyl residues that regulate the enzyme activity [36, 37]. Their sulfohydryl groups are susceptible to modification by ROS, nitric oxid, lipid peroxidation products and S-glutathionylation [38-42]. Modification through glutathionylation of NADP-ICDH from the HEK293 cells and intact respiring rabbit heart mitochondria treated with oxidants may lead to a slight disruption of protein structure 
Table 2. Kinetic proprieties of the purified mitochondrial NADP-Isocitrate dehydrogenase from the normoxic and ischemic rat heart

\begin{tabular}{lcc}
\hline Parameters & Normoxia $^{a}, \mu \mathrm{M}$ & Ischemia $^{a}, \mu \mathrm{M}$ \\
\hline $\mathrm{K}_{\mathrm{m}}$ isocitrate & $45 \pm 5$ & $17 \pm 6^{*}$ \\
$\mathrm{~K}_{\mathrm{m}} \mathrm{NADP}$ & $46 \pm 5$ & $46 \pm 4$ \\
$\mathrm{~K}_{\mathrm{m}} \mathrm{Mn}^{2+}$ ions & $420 \pm 15$ & $150 \pm 10^{*}$ \\
$\mathrm{~K}_{\mathrm{i}} \mathrm{Fe}^{2+}$ ions & $50 \pm 4(2)$ & $50 \pm 3(2)$ \\
$\mathrm{K}_{\mathrm{i}} \mathrm{H}_{2} \mathrm{O}_{2}$ & $450 \pm 50(3)$ & $1630 \pm 48^{*}(3)$ \\
$\mathrm{K}_{\mathrm{i}}\left(\mathrm{Fe}^{2+}+\mathrm{H}_{2} \mathrm{O}_{2}\right)$ & $15 \pm 2(2)$ & $25 \pm 3^{*}(2)$ \\
$\mathrm{K}_{\mathrm{i}}$ glutathione & $150 \pm 32(3)$ & $n 0^{*}$ \\
$\mathrm{~K}_{\mathrm{i}}$ citrate & $159 \pm 29(1)$ & $280 \pm 41^{*}(1)$ \\
$\mathrm{K}_{\mathrm{i}}$ 2-oxoglutarate & $80 \pm 26(1)$ & $250 \pm 30^{*}(1)$ \\
\hline
\end{tabular}

${ }^{a}$ The results are expressed as the means + S.D. derived from three experiments. $\left.{ }^{*}\right)$ Statistical significant values, $P<0.05$. In brackets is marked the type of inhibition: 1 - competitive; 2 - non-competitive; 3 - mixed.

[42]. It was proposed that this mechanism of activity regulation might prevent enzyme from further oxidation by ROS to its irreversible forms [42]. Moreover, the glutathionylated NADP-ICDH is more resistant to protease action and digestion, presumably through slight conformational changes of its molecules. However, it must be pointed out, that the glutathionylation can inhibit the mitochondrial NADP-ICDH, when the production of oxidants exceeds antioxidant capacity [42]. According to our data, mobilisation of the antioxidant system took place in rat heart mitochondria during occlusion of the left coronary artery for 45 minutes [32]. Therefore, NADP- ICDH may participate in the cellular defence system against oxidative damage by supplying NADPH to mitochondria needed for the regeneration of GSH. Increasing enzyme activity under the referred conditions may support this conclusion.

Our study of the influence of metabolites, which organelle content could be changed under ischemia, on the normoxic and ischemic enzyme behaviour showed that the concentrations of ATP and ADP can regulate the activity of NADPIDH under ischemic conditions. It is known that the ATP degradation [13] related to breaking synthesis [8], transport [43] and ATP utilisation [44], and ADP accumulation leads to the decrease of ATP/ADP ratio, which is considered as an indicator of radical metabolic changes under ischemia. A non-reversible ischemic damage and cell necrosis of cardiomyocites was accompanied by a $50 \%$ decrease of initial ATP concentrations to $3.5 \mu \mathrm{M}[4,44]$. We showed that the ATP increase from 3.5 to $250 \mu \mathrm{M}$ caused a slight increase of enzyme activity in ischemic mitochondria $(118 \pm 3 \%$, at $7 \mu \mathrm{M}$ ATP) when an enzyme inhibition was observed at normoxia (Fig. 3A). At the same time, a slight inhibition by ADP was observed at concentrations ranging from 5.0 to $40.0 \mu \mathrm{M}$ for normoxic and from 2.5 to $250 \mu \mathrm{M}$ for ischemic enzyme (Fig. 3A). The absence of an ATP inhibition and a stronger inhibitory effect of ADP at the physiological concentrations
Table 3. Effects of malate, succinate and fumarate on the activities of NADPisocitrate dehydrogenase from the normoxic and ischemic rat myocardium

\begin{tabular}{|c|c|c|c|}
\hline Metabolites & $\begin{array}{l}\text { Concentration, } \\
\mathrm{mM}\end{array}$ & $\begin{array}{l}\text { Activity of } \\
\text { NADP-ICDH, } \\
\text { normoxia }\end{array}$ & $\begin{array}{l}\% \text { from the } \\
\text { control value } \\
\text { Ischemia }\end{array}$ \\
\hline Malate & $\begin{array}{l}0.1 \\
0.25 \\
0.5 \\
1 \\
1.5\end{array}$ & $\begin{array}{l}90 \pm 4 \\
87 \pm 4 \\
85 \pm 5 \\
83 \pm 7 \\
80 \pm 5\end{array}$ & $\begin{array}{l}60 \pm 4^{*} \\
55 \pm 5^{*} \\
52 \pm 4^{*} \\
40 \pm 6^{*} \\
35 \pm 4^{*}\end{array}$ \\
\hline Succinate & $\begin{array}{l}0.1 \\
0.25 \\
0.5 \\
1 \\
1.5\end{array}$ & $\begin{array}{l}85 \pm 6 \\
80 \pm 4 \\
74 \pm 5 \\
70 \pm 4 \\
65 \pm 4\end{array}$ & $\begin{array}{l}80 \pm 4 \\
77 \pm 6 \\
74 \pm 6 \\
70 \pm 5 \\
65 \pm 5\end{array}$ \\
\hline Fumarate & $\begin{array}{l}0.1 \\
0.25 \\
0.5 \\
1 \\
1.5\end{array}$ & $\begin{array}{l}78 \pm 4 \\
74 \pm 4 \\
73 \pm 5 \\
70 \pm 4 \\
68 \pm 3\end{array}$ & $\begin{array}{l}72 \pm 4 \\
65 \pm 3 \\
65 \pm 6 \\
63 \pm 5 \\
60 \pm 6\end{array}$ \\
\hline
\end{tabular}

${ }^{a}$ The results are expressed as the means \pm S.D. derived from 3-5 experiments. $\left.{ }^{*}\right)$ Statistical significant values, $P<0.05$.

under ischemia could reflect other metabolic functions of this enzyme under oxidative stress $[4,12,45]$.

We also analysed the influence of some di- and tricarboxylic acids, including 2-oxoglutarate, citrate, malate, fumarate and succinate, on NADP-ICDH activity from both tissues. Inhibitory effects of these intermediates on NADPICDH were detected. But the effects of citrate, 2-oxoglutarate and malate were different for the enzyme from the normoxic and ischemic tissues. The 2-oxoglutarate behaved as a competitive inhibitor with respect to isocitrate. $\mathrm{K}_{\mathrm{i}}$ for 2oxoglutarate had values of 80 and $205 \mu \mathrm{M}$, for the normoxic and ischemic enzyme, respectively (Table 2). On the contrary, citrate (Table 2) and malate (Table 3) were stronger inhibitors of NADP-IDH under ischemia than at normoxia, while the fumarate and succinate had no significant effect on the enzyme activity (Table 3 ). These results may indicate that mitochondrial NADP-ICDH under ischemic conditions exhibited an abnormal catalytic behaviour. Interestingly, the strongest NADP-ICDH inhibitor at normoxia, 2oxoglutarate, had lower inhibitory effect under ischemia. It should be taken into account that 2-oxoglutarate serves as the main nitrogen acceptor and it is a precursor of glutamate $[18,20]$. Hence, under ischemia the changes of enzyme behaviour in relation to 2-oxoglutarate can stimulate the amino acids biosynthesis [46] and utilisation of accumulated the TAC intermediates [43]. At the same time it could be also proposed that the increase of the enzyme activity and substrate affinity under ischemia may promote the enhancement of NADPH supply for the GRGP-system, activity of which increases during oxidative stress [13,47]. 


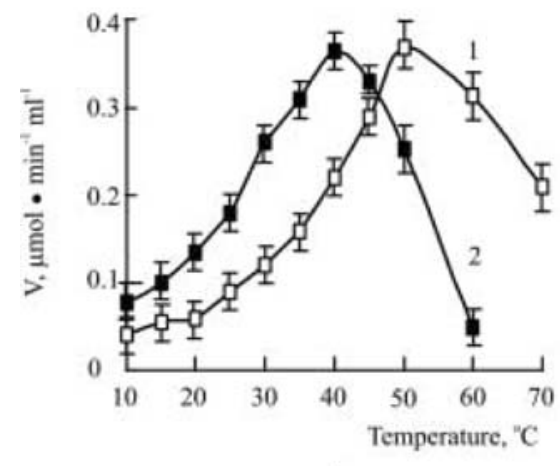

A

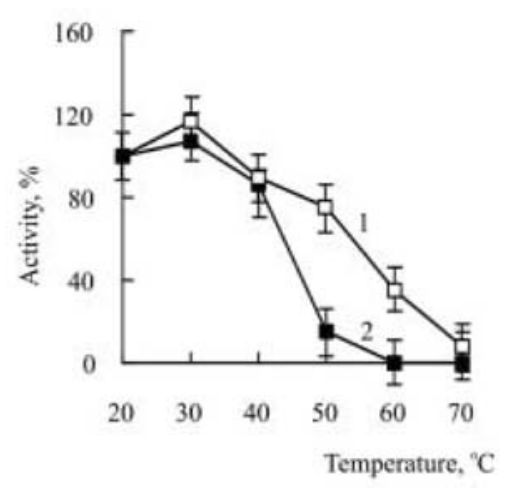

C

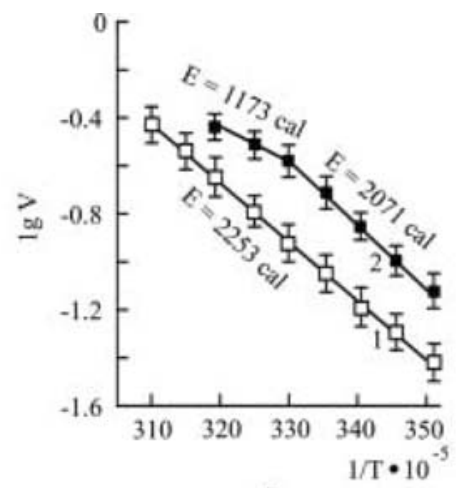

B

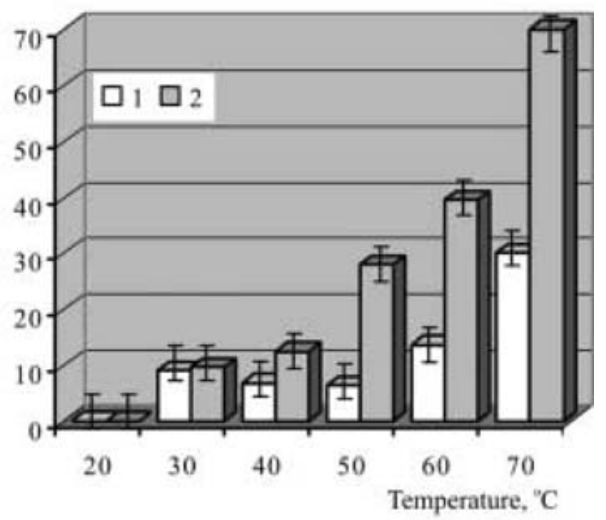

D

Fig. 2. The influence of temperature on NADP-isocitrate dehydrogenase activity from normoxic (1) and ischemic (2) rat heart mitochondria. A. Determination of the enzyme temperature optimum. Data are means \pm S.D. $(n=4)$ B. Arrhenius plot of the data from $10^{\circ} \mathrm{C}$ to $50^{\circ} \mathrm{C}$ and $10^{\circ} \mathrm{C}$ to $40^{\circ} \mathrm{C}$. Data are means \pm S.D. $(n=4)$. C. Determination of the enzyme thermo-inactivation. Data are means \pm S.D. $(n=4)$. D. Determination of the enzyme thermostability. Determination of the enzyme thermostability was estimated spectrophotometrically by measuring the magnitudes of light diffusion value $(\tau)$ of NADP-isocitrate dehydrogenase preparations at $490 \mathrm{~nm}$. The results are expressed as the means + S.D. $(n=4)$.

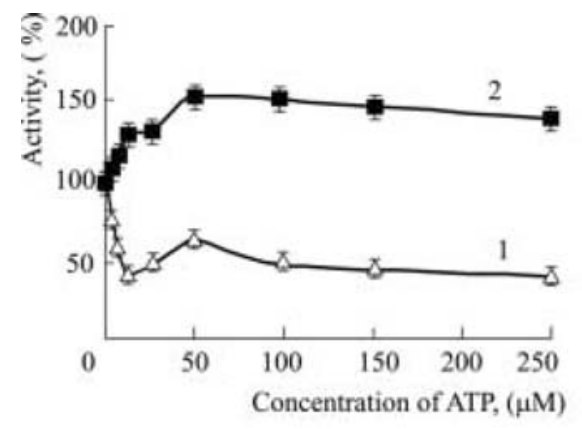

A

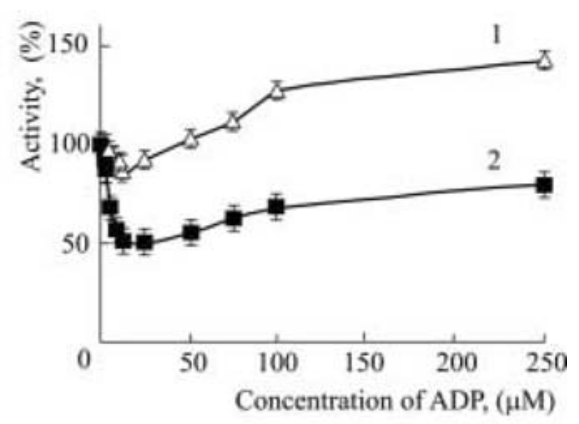

B

Fig. 3. The influence of ATP (A) and ADP (B) on NADP-isocitrate dehydrogenase activity from normoxic (1) and ischemic (2) rat heart mitochondria. The results are expressed as the means + S.D. derived from three experiments. 


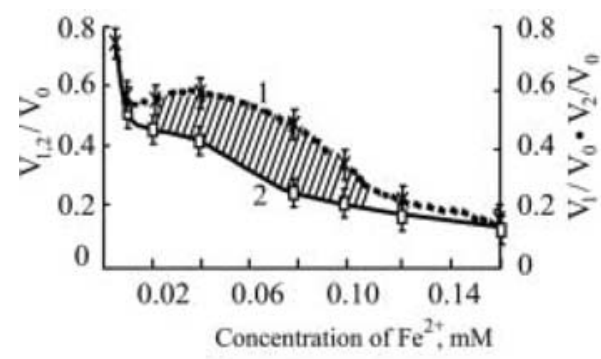

I

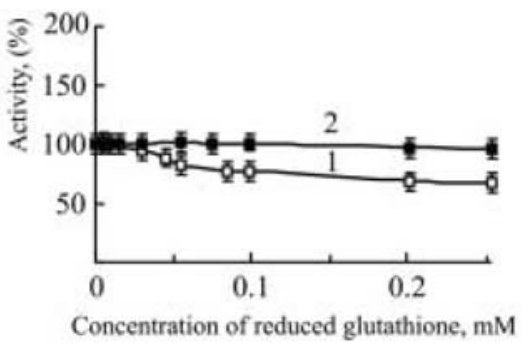

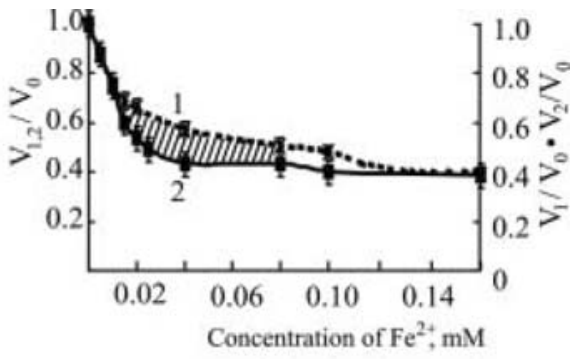

II

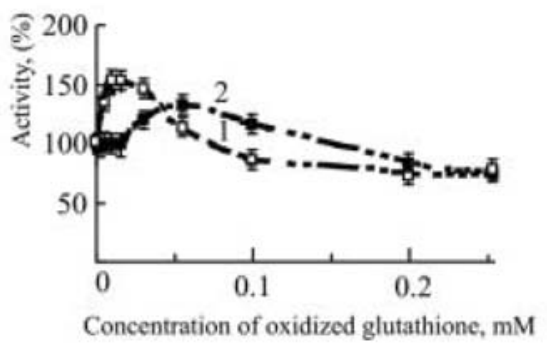

B

Fig. 4. The influence of $\mathrm{Fe}^{2+}$ and $\mathrm{H}_{2} \mathrm{O}_{2}$ mixture (A) and glutathione (B) on NADP-isocitrate dehydrogenase activity from normoxic (1) and ischemic (2) rat heart mitochondria. Determination of the type of $\mathrm{Fe}^{2+}$ and $\mathrm{H}_{2} \mathrm{O}_{2}$ co-operation during inhibition of NADP-isocitrate dehydrogenase from mitochondria of normoxic (I) and ischemic (II) rat heart was performed according to Kurganov. The enzyme activity assayed as a function of NADPH concentrations using 0.4 mM NADP, $0.2 \mathrm{mM} \mathrm{MnCl}_{2}$ and $0.05 \mathrm{mM}$ isocitrate in the presence of $0.10 \mathrm{mM} \mathrm{H}_{2} \mathrm{O}_{2}$. The $0.02-0.16 \mathrm{mM}$ concentration range of Fe $\mathrm{F}^{2+}$ ions were used. $1-$ $\mathrm{V}_{1,2} / \mathrm{V}_{0}$ - ratio of the enzyme reaction velocity in the presence or absence of two inhibitors; $\mathrm{V}_{1} / \mathrm{V}_{0} \times \mathrm{V}_{2} / \mathrm{V}_{0}$ - product of ratio of the enzyme reaction velocity at the presence of the first inhibitor $\left(\mathrm{Fe}^{2+}\right.$ ions) and the second inhibitor $\left(\mathrm{H}_{2} \mathrm{O}_{2}\right)$ to initial velocity. Data are means \pm S.D. $(n=5)$.

The influence of substrates of the Fenton reaction on the NADP-ICDH activity was evaluated. Strong inhibition of NADP-ICDH by $\mathrm{H}_{2} \mathrm{O}_{2}$ in mitochondria of healthy rats was observed (Table 2). At the same time, the inhibitory effect of $\mathrm{Fe}^{2+}$ was not different at both normoxic and ischemic conditions. However, when combined, $\mathrm{Fe}^{2+}$ and $\mathrm{H}_{2} \mathrm{O}_{2}$ exhibited pronounced inhibitory effect at normoxia (lower $\mathrm{K}_{\mathrm{i}}$ values) when compared with ischemia (higher $\mathrm{K}_{\mathrm{i}}$ values) (Table 2). The analysis of interactions between these two inhibitors allow us to conclude that the NADP-ICDH inhibition by $\mathrm{Fe}^{2+}$ and $\mathrm{H}_{2} \mathrm{O}_{2}$ was characterised by a synergistic effect expressed in a lower extent under ischemic conditions (Fig. 4A). $\mathrm{Fe}^{2+}$ and $\mathrm{H}_{2} \mathrm{O}_{2}$ interactions lead to the formation of hydroxyl radical, an aggressive ROS species. Therefore, decrease of the NADP-ICDH activity can be associated with the enzyme oxidation through the carbonylation. This suggestion is consistent with the fact that protein carbonylation was a common biomarker of severe oxidative damage in proteins [48]. It cannot be excluded that regulation of the enzyme by $\mathrm{Fe}^{2+}$ and $\mathrm{H}_{2} \mathrm{O}_{2}$ might be connected with its participation in the NADPH generation for the GRGP-system. Under ischemia, the lowest enzyme repression in the presence of the compo- nents of the Fenton reaction can also increase NADPH level and activate the GRGP-system.

Under our experimental conditions the reduced glutathione inhibited NADP-ICDH from the normoxic heart mitochondria at the concentrations ranging from 5 to $100 \mu \mathrm{M}$, while had no inhibitory effect on the enzyme from ischemic mitochondria (Fig. 4B, Table 2). On the contrary, oxidised glutathione activated the NADP-IDH from the ischemic mitochondria at the concentrations ranging from 25 to $125 \mu \mathrm{M}$, whereas it had weaker effect on the enzyme from the normoxic tissue (Fig. 4B). NADP-ICDH activity increased in $10 \pm 2 \%$ and $53 \pm 2 \%$ in the presence of $10 \mu \mathrm{M}$ oxidised glutathione at normoxia and ischemia, respectively. These data suggest that the reduced and oxidised glutathione have different regulatory effects on the activity of the mitochondrial NADP-IDH at the normoxic and ischemic conditions. The observed regulatory effects could be important in the mitochondrial NADP-ICDH and the GRGP-system interaction in a rat heart under increasing ROS production.

NADP-ICDH activation coupled with the increasing NADPH production due to particular kinetic and regulatory enzyme changes can lead to the growth of reduced/oxidized 
glutathione ratio, which in turn is determined by the GP activation. This supposition remains in contradiction with the reverse metabolic flux through NADP-ICDH and its hypothesized role in the fine regulation of the TCA activity [23]. On the other hand, it is consistent with the suggestion of Jo et al. [15] based on evidence of antioxidant role of the enzyme obtained from N1H3T3 cells. It must be taken into account that in heart the mitochondrial NADPH/NADP ratio is more than $50[49,50]$, when in the N1H3T3 cells was less than 1 [23]. Nevertheless, under conditions of severe oxidative stress created in myocardium, during ischemia the main consequences of the TAC repression would be the decrease of NADH level and suppression of the electron transport. NADH availability can limit the activity of transhydrogenase to the enhancement of NADPH generation [23, 51]. Some other evidences related to the antioxidant role of the mitochondrial NADPICDH were also reported [39, 52, 53].

It cannot be excluded that changes in the NADP-ICDH behaviour under ischemia might have a regulatory significance for the functioning of the myocardial antioxidative GRGPsystem. Higher catalytic activity, $\mathrm{K}_{\mathrm{m}}$, and differential sensitivity of NADP-ICDH to several metabolites can be explained on the grounds of adaptation strategies to the oxidative stress and tissue recovery.

\section{Acknowledgments}

This work was supported by grants from the Scientific Programs of Russia Ministry Education and Science (number of projects are RNP. 2.1.1.4429 and UR. 07.01.004).

\section{References}

1. Nakasava H, Arroyo C., Ichimori, K: Ischemia-reperfusion injury and toxicity of free radicals. J Mol Cell Cardiol 22(2): 13, 1990

2. Ruuge EK, Ledenev AN, Lakomkin VL: Free radical metabolites in myocardium during ischemia and re-perphusion. Amer J Physiol 261(4): 81-86, 1991

3. Guarneru G, Muskari C, Ventura C: Effect of ischemia on heart submitochondrial superoxide production. Free Radicals Res Communs 1(2): 123-128, 1985

4. Meerson FZ: The failing heart. Adaptation and de-adaptation. N.Y.: Raven press, 1983

5. Skulachev VP: Role of uncoupled and non-coupled oxidations in maintenance of safely low levels of oxygen and its one-electrone reductants. Q Rev Biophys 29: 169-203, 1996

6. Korshunov SS, Skulachev VP, Starkov AA: High potential actuates a mechanism of production of reactive oxygen species in mitochondria. FEBS Lett 416: 15-18, 1997

7. Esposito LA, Melov S, Panov A, Cottrell BA, Wallace DC: Mitochondrial disease in mouse results in increased oxidative stress. Proc Natl Acad Sci USA 96(9): 4820-4825, 1999

8. Chambers DE, Parks DA, Patterson G, Roy R, McCord JM, Yoshida S, Parmley LF, Downey JM: Xanthine oxidase as a source of free radical damage in myocardial ischemia. J Mol Cell Cardiol 17(2): 145-152, 1985

9. Rao PS, Cohen MV, Mueller HS: Production of free radicals and lipid peroxides in early experimental myocardial ischemia. J Mol Cell Cardiol 15(10): 713-716, 1983

10. Halliwell B, Gutteridge JM: The importance of free radicals and catalytic metal ions in human diseases. Mol Aspects Med 8(2): 89-193, 1985

11. Skulachev VP: Membrane-linked systems, preventing superoxide formation. Bioscience Reports 17(3): 347-366, 1997

12. Flint DH, Tuminello JF, Emptage M: The inactivation of Fe-S cluster containing hydrolyases by superoxide. J Biol Chem 268: 22369-22376, 1993

13. Osipov AN, Azizova OA, Vladimirov YA: Active oxygen species and their role in the organism. Uspekhi biologicheskoi khimii 31: 180-208, 1990

14. Pfeifer R, Rarl G, Scholz R: Does the pentose cycle plays a major role for NADPH supply in the heart? Biol Chem Hopp-Seyler 367(10): 1061-1068, 1986

15. Jo SH, Son MK, Koh HJ, Lee SM, Song IH, Kim YO, Lee YS, Jeong KS, Kim WB, Park JW, Song BJ, Huh TL: Control of mitochondrial redox balance and cellular defense against oxidative damage by mitochondrial NADP-dependent isocitrate dehydrogenase. J Biol Chem 276: 1616816176, 2001

16. Pastuszko A, Gromek A: Effect of free fatty acids on the activity of NADP-dependent isocitrate dehydrogenase in normal and pathological conditions. Bull Acad Pol Sci Ser Sci Biol 24(7): 415-422, 1976

17. Islam M, Joyce L, Bell L, Baron DN: Purification and comparative properties of isoenzymes of NADP-isocitrate dehydrogenase from rat heart and liver. Biochem J 129(5): 1003-1011, 1972

18. Galvez S, Gadal P: The function of the NADP-dependent isocitrate dehydrogenase isoenzymes in living organisms. Plant Science 105: 111,1995

19. Seelig GF, Colman RF: Characterization of the physicochemical and catalytic properties of human heart NADP-dependent isocitrate dehydrogenase. Arch Biochem Biophys 188(2): 394-409, 1978

20. Medvedeva LV, Popova TN, Artiuykhov VG, Matasova LV, Pinheiro de Carvalho MAA: Free radical processes intensity and activity regulation of cytoplasmic NADP-isocitrate dehydrogenase in rat heart at norm and ischemia // Biochem. (Mosc) 67(6): 696-705, 2002

21. Lowenstein JM: The tricarboxylic acid cycle In: Metabolic Pathways. Edited by Greenberg DM. New York: Academic, p. 147-267, 1967

22. Luo H, Shan X, Wu J: Expression of human mitochondrial NADPdependent isocitrate dehydrogenase during lymphocyte activation. J Cell Biochem 60: 495-507, 1996

23. Comte B, Vincent G, Bouchard B, Benderdour M, Des Rosiers C: Reverse flux through cardiac NADP-isocitrate dehydrogenase under normoxia and ischemia. Am J Physiol Heart Circ Physiol 283(4): H1505H1514, 2002

24. Jonassen AK, Aasum E, Riemersma RA, Mjos OD, Larsen TS: Glucoseinsulin-potassium reduces infarct size when administered during reperfusion. Cardiovasc Drugs Ther 14(6): 615-623, 2000

25. Lowry OH, Rosebrough NJ, Farr AL, Randall RJ: Protein measurement with the Folin Phenol reagent. J Biol Chem 139: 265-275, 1951

26. Yu J, Steck TL: Isolation and characterization of band 3 , the predominant polypeptide of the human erythrocyte membrane. J Biol Chem 250: 9170-9175, 1975

27. Davis BJ: Disc electrophoresis. II Method and application to serum protein Ann. N.Y. Acad Sci 121: 404-407, 1964

28. Maurer G: Disk Electrophoresis [Russian translation]. Mir, Moscow, 1971

29. Kulkarni AP, Mehrotra KN: Estimation of molecular parameters of proteins by gel chromatography on Sephadex G-150. Anal Biochem 38(1): $285-288,1970$ 
30. Kurganov BI: Allosteric enzymes. Mcy;oscow: Science, 1978

31. Dixon M, Webb EC: Enzymes, 3rd edn. USA Acad. Press Inc., NY, 1979

32. Medvedeva LV, Popova TN, Artyukhov VG, Matasova LV, Akatova RV: Oxidative status and distribution of NADP-dependent isocitrate dehydrogenase and aconitate hydratase in rat cardiomyocytes under normal conditions and during ischemia. Bull Exp Biol Med 134(2): 130-134, 2002

33. Meerson FZ: Pathogenesis and prevention of stress and ischemic heart injury. Moscow, Medicina, p 272, 1984

34. Penny JE, Kukumus JR, Tyrer JH. Eadic MJ: Quantitative oxidative enzyme histochemistry of the spinal cord. Part 2. Relation of cell size and enzyme activity to vulnerability to ischemia. J Neurol Sci 26(2): $187-192,1975$

35. Popova TN: Isocitrate dehydrogenases: forms, localization, properties and regulation. Biochemistry (Moscow). 58(12): 1861-1879, 1993

36. Smyth GE, Colman RF: Cysteinyl peptides of pig heart NADPdependent isocitrate dehydrogenase that are modified upon inactivation by N-ethylmaleimide. J Biol Chem 266: 14918-14925, 1991

37. Fatania HR, Al-Nassar KE, Thomas N: Chemical modification of rat liver cytosolic NADP(+)-linked isocitrate dehydrogenase by $\mathrm{N}$ ethylmaleimide. Evidence for essential sulphohydryl groups. FEBS Lett 322: 245-248, 1993

38. Lee SM, Huh TL, Park J-W: Inactivation of NADP(+)-dependent isocitrate dehydrogenase by reactive oxygen species. Biochimie (Paris) 83: 1057-1065, 2001

39. Yang ES, Richter C, Chun JS, Huh TL, Kang SS, Park JW: Inactivation of NADP(+)-dependent isocitrate dehydrogenase by nitric oxide. Free Radic Biol Med 33: 927-937, 2002

40. Yang JH, Yang ES, Park JW: Inactivation of NADP ${ }^{+}$-dependent isocitrate dehydrogenase by lipid peroxidation products. Free Radic Res 38(3): 241-249, 2004

41. Benderdour M, Charron G, DeBlois D, Comte B, Des Rosiers C: Cardiac mitochondrial $\mathrm{NADP}^{+}$-isocitrate dehydrogenase is inactivated through 4-hydroxynonenal adduct formation: an event that precedes hypertrophy development. J Biol Chem 278: 45154-45159, 2003
42. Kil IS, Park J-W: Regulation of mitochondrial NADP-dependent isocitrate dehydrogenase activity by glutathionylation. J Biol Chem 280(11): 10846-10854, 2005

43. Gatsura VV: Pharmacological correction of the energy metabolism of the ischemic myocardium. Pharmacol Ther 27(3): 297-332, 1985

44. Reimer KA, Hill ML, Jennings RB: Prolonged depletion of ATP and of adenine nucleotide pool due to delayed re-synthesis of adenine nucleotides following reversible myocardial injury in dogs. J Moll Cell Cardiol 13(2): 229-240, 1981

45. Sazanov LA, Jackson JB: Proton-translocating transhydrogenase and NAD- and NADP-linked isocitrate dehydrogenases operate in a substrate cycle which contributes to fine regulation of the tricarboxylic acid cycle activity in mitochondria. FEBS Lett 344(2-3): 109-116, 1994

46. Cerri C, Fici F, Scarlato G: $\alpha$-Ketoglutarate induced transamination during ischemic exercise. Adv Exp Med Biol 153: 473-478, 1982

47. Nohl H, Jordan W: The metabolic fate of mitochondrial hydrogen peroxide. Europ J Biochem 111: 203-210, 1980

48. Dalle-Donne I, Giustarini D, Colombo R, Rossi R, Milzani A: Protein carbonilation in human diseases. Trends Mol Med 9: 169-176, 2003

49. Flagg TP, Nichols CG: Sarcolemmal $\mathrm{K}_{\mathrm{ATP}}$ channels in the dark: molecular mechanisms brought to light, but physiologic consequences still in the dark. J Cardiovasc Electrophysiol 12: 1195-1198, 2001

50. Sundqvist KE, Heikkila J, Hassinen IE, Hiltunen JK: Role of NADP (corrected)-linked malic enzymes as regulators of the pool size of tricarboxylic acid-cycle intermediates in the perfused rat heart. Biochem J 243: 853-857, 1987

51. Kehrer JP, Lund LG: Cellular reducing equivalents and oxidative stress. Free Radic Biol Med 17: 65-75, 1994

52. Kim HJ, Kang BS, Park JW: Cellular defense against heat shock-induced oxidative damage by mitochondrial $\mathrm{NADP}^{+}$-dependent isocitrate dehydrogenase. Free RadicRes 39(4): 441-448, 2005

53. Kil IS, Huh TL, Lee YS, Lee YM, Park JW: Regulation of replicative senescence by NADP(+)-dependent isocitrate dehydrogenase. Free Radic Biol Med 40(1): 110-119, 2006 